\title{
Tackling Transition: Exposing Secondary School Students to Tertiary IT Teaching and Learning
}

\author{
Judy Sheard, Gordon Lowe, Ann Nicholson, and Jason Ceddia \\ Monash University, Australia
}

\author{
¡udy.sheard@csse.monash.edu.au Gordon.Lowe@infotech.monash.edu.au \\ Ann.Nicholson@infotech.monash.edu.au iceddia@csse.monash.edu.au
}

\section{Executive Summary}

Students entering university from school often experience difficulties as they adapt to tertiary life. During this time of transition, students must adjust to new teaching and learning environments as well as different social and physical environments. Students in computing degree programs face particular problems. For example, they can have misconceptions about studying computing at university because their experiences with computers at home or at school usually bear little resemblance to what they study in a tertiary computing degree. Research has identified the key issues relating to transition, however the methods to address this problem to date have had mixed success.

In this paper we discuss an approach to tackling the transition problem. In 1999 the "Smart House" project was developed for an IT Summer School. This project aimed to address transition issues by helping secondary school students make informed tertiary study choices and preparing them for changes they may experience in moving to university. The development and implementation of the Smart House project was a collaborative initiative from staff representing four undergraduate degree programs within the Faculty of Information Technology of Monash University, Australia. The project was designed to demonstrate the application and relevance of computing to everyday life. It required a carefully planned teaching and learning environment, and specifically designed teaching resources, to create a cohesive project which encompassed a broad range of computing topics and provided a worthwhile educational experience. The Smart House project has been run for five successive Summer Schools and evaluation of feedback from students, parents and teachers indicates that the project has been successful in meeting its objectives of addressing transition issues of future computing students.

This paper presents an overview of the transition problem and in particular the difficulties faced by first year computing students. An outline of the Smart House project and the specific aspects of the project that address transition issues are described. Results of a follow-up study of participating students in their first year of university are presented, and the effectiveness of the Smart House project and Summer School in providing students with knowledge of computing degree programs and a realistic view of the tertiary teaching and learning environment is evaluated.

Material published as part of this journal, either on-line or in print, is copyrighted by the publisher of the Journal of Information Technology Education. Permission to make digital or paper copy of part or all of these works for personal or classroom use is granted without fee provided that the copies are not made or distributed for profit or commercial advantage AND that copies 1) bear this notice in full and 2) give the full citation on the first page. It is permissible to abstract these works so long as credit is given. To copy in all other cases or to republish or to post on a server or to redistribute to lists requires specific permission and payment of a fee. Contact Editor@JITE.org to request redistribution permission.
Keywords: transition, Smart House, university experience, Summer School, computing courses

\section{Introduction}

Students moving from secondary school to university experience a period of transition in which they face major changes in their lives. For some students this is a smooth process, however many encounter difficulties that range from minor is- 
sues of settling in to significant problems of adaptation which have a long-term impact on their future. Transition problems are characterised by the first year student population experiencing high dropout rates, low pass rates, and achieving lower grades than expected. At a conference at Monash University in 1994 that was convened to explore the problem of transition, Pargetter (1995) reported that "up to $40 \%$ of [Monash] students in first year experience a significantly less successful year than they had in year twelve" and this is despite the fact that Monash generally takes students from the top end of the year twelve cohort, as ranked by their university entry scores.

The dissatisfaction and low achievements of students in transition was highlighted in a national study of 4068 first year students in Australian universities, conducted in 1994 by McInnis and James (1995). A survey of the students at the end of their first semester found that, of the first year students who were school leavers:

- $23 \%$ were dissatisfied with university;

- $43 \%$ were achieving lower marks than they expected;

- $30 \%$, in hindsight, felt that they were not ready to choose a university course during their final year of school.

McInnis, James and Hartley (1999) completed another survey of 2609 first year students in 1999. This study found a small increase in students who were enjoying their course overall (61\% in 1994 to $64 \%$ in $1999)$ and an increase in students who were satisfied with their initial university experience $(61 \%$ in 1994 to $63 \%$ in 1999). The new study also found a shift towards finding university more fulfilling than school (57\% in 1994 to $64 \%$ in 1999) and fewer students finding university more demanding than school (64\% in 1994 to $57 \%$ in 1999). However, there was still evidence of widespread problems with transition, with $20 \%$ of the students hoping to change to another course and $30 \%$ considering deferring, claiming that they were not ready to choose a course. This study also found that motivations for tertiary study were the same as found in the 1994 study. These findings are supported by other studies. A qualitative study by Kantanis (2000) found that Arts students were achieving lower marks than expected (as compared to year 12). Other studies provide an international perspective on this problem (Braxton, Vesper \& Hossler, 1995; Gale, Andrews, Biddle \& Brown, 1997; Pascarella \& Terenzini, 1991).

A major initiative to address the transition problem, the Monash Transition program, was established in 1995 at Monash University. The aim of this program is to investigate problems faced by first year university students, and a number of research projects have since been conducted under its auspices. Specific outcomes from this research have recommended the development of programs to provide secondary school students with awareness and understanding of degree program structure and content, and a first-hand experience of the university environment (Peel, 1998a; Peel, 1998b). A transition research project by Peel (1998b) in 1996 and 1997 found that both secondary school students and teachers expressed a strong desire for interactive discussion with university teachers and particularly university students. They claimed that the most useful information for prospective students had been gained from school liaison activities that were program specific, rather than the more general institutional marketing exercises such as university open days.

In response to the transition research, in 1999 the Faculty of Information Technology (FIT) of Monash University established an annual IT Summer School. This is a week long residential program, held during the Summer holidays, for students who are about to enter the final two years of their secondary schooling. The aim of the Summer School is to provide participants with an awareness of IT degree programs and career options, and in particular, the undergraduate degree programs in FIT. In 1999 the "Smart House" project was developed for the IT Summer School. Following recommendations from the Monash Transition program, this project aimed to confront the transition problem before students entered university by giving them a realistic insight into the type of study style and content they can expect 
to find in a tertiary environment. It was felt this experience would help them make informed degree program choices and prepare them for the transition to university.

The development and implementation of the Smart House project was a collaborative initiative from staff representing four undergradua te degree programs within FIT. The project was designed to demonstrate the application and relevance of computing to everyday life. It required a carefully planned teaching and learning environment, and specifically designed teaching resources to create a cohesive project which encompassed a broad range of computing topics and provided a worthwhile educational experience.

The remainder of this paper presents an overview of the transition problem, and, in particular, the difficulties faced by first year computing students. An outline of the Smart House project and the specific aspects of the project that address transition issues are described. Results of surveys and a follow-up study of participating students in their first year of university are presented. These have shown the effectiveness of the Smart House project and Summer School in providing students with knowledge of computing degree programs and a realistic view of the tertiary teaching and learning environment.

\section{Transition Issues of Computing Students}

The effects of unsuccessful transition from school to university can be devastating for students and their families, and have long-term negative outcomes in terms of loss of self-esteem and motivation (Parge tter, 1995). Studies have shown that students experience problems with transition for a variety of reasons. Pascarella and Terenzini (1991) present an investigation on the many ways that students may be changed by their university experiences. These include, in particular, psychological changes such as self-esteem and sense of identity. Another study by Braxton, Vesper and Hossler (1995) reports on academic and social issues of transition from a longitudinal study of 263 first year students in North American colleges. Kantanis (2000) in her study of Australian first year university Arts students also found that most problems fall into the categories of academic and social adaptations, although these often interrelate in a complex mix of issues. These studies suggest that to effectively assist with the transition process, both academic and social issues need to be addressed. The following sections highlight the major factors in academic and social transition of first year computing students. While transition issues apply to all faculties, the discussion below will generally focus on the specific problems faced by computing students.

\section{Academic Transition}

\section{Awareness of computing degree program options}

Choosing an appropriate degree program that matches students' expectations and abilities is recognised as a major factor in successful transition to university (James, 2000). It is therefore important that students make an informed choice of their tertiary study. Students need information about the structure and content of the degree programs they are considering to provide an understanding of what tertiary study in the particular discipline involves. Peel (1998b) argues that students often receive conflicting advice from parents, teachers, friends and careers advisors, and upon entering university there can be a mismatch between expectations and actual experiences. The difficulty students may have in obtaining informed advice was highlighted by a 1996 survey of 59 Melbourne secondary schools within a $10 \mathrm{Km}$ radius of the main campus of Monash University. This survey found that career advisors and teachers knew very little about computing degree programs offered at Monash (Abramson, Lowe \& Atkinson, 2000). 
A further concern is the low percentages of female students in computing programs. There is a general perception that computing is focused on technology and this is often seen as a male domain. However, Teague (1998) claims that many females mistakenly believe that they would not be any good at computing and that a computing program would not be of interest to them. This is supported by an Australian study of attitudes towards technology and career skills, involving 350 participants. This study found that only $3 \%$ of females rejected IT because it was, as they term "too blokey", instead they report:

"Basically, young females are just not interested in IT. 50\% say that the fact that it is too boring would prevent them from becoming interested. They are also concerned that IT is isolating and does not involve sufficient teamwork and social interaction." (Reality Bytes, 2001, p41).

The report also stated that while $25 \%$ of year 12 students undertake IT as a course of study in year 12 , $65 \%$ of these are male. Furthermore it states, "This gender imbalance is even more acute in higher education where $81 \%$ of IT enrolments are male" (Reality Bytes, 2001, p35).

Within most computing degrees in FIT difficulties are caused by low entry levels compared to other programs. Computing degree programs attract some students who did not select a computing degree as their first preference, but are studying computing because they could not gain entry into the programs higher up on their list of preferences. A study in 1997 of a group of FIT computing students who had failed an introductory programming subject revealed that a high percentage $(66 \%)$ had not chosen computing as a first option (Sheard \& Hagan, 1998).

Students who have an interest in studying computing at Monash often have difficulty choosing a degree program because of the large number of options available. There are currently twelve undergraduate computing programs in FIT and, in addition, there are a number of double degree combinations. Across these programs there is a lot of overlap in topic areas, and although each has a unique focus, it is difficult for potential students to differentiate between them. It is important for students to choose their computing course carefully, because with the different course requirements and core subjects, once a student gains entry to a course it is not always easy to later move between courses.

\section{Knowledge of course content and expectations}

Problems occur when students find themselves in tertiary programs in which they have little interest, and therefore a low motivation to learn. The study by McInnis, James and Hartley (1999) showed that many students discover that their chosen discipline area is different to what they expected and this is a source of disappointment and discouragement. This is particularly true in computing programs. Gale, Andrews, Biddle and Brown (1997) reported on the misconceptions students have about tertiary computing courses. Students' ideas of computing study are often based on personal experiences, for example, computer games, word processors, chat rooms; all of which bear little resemblance to what they study in a computing degree. The study of first year programming students by Sheard and Hagan (1998) found many students remarked that computing subjects were complex and the workload was heavy. Some students had not studied computing at school, or, if they had, they found that subjects in a computing course at university were quite different in content to computing subjects at school. A reason for this was identified by the survey in 1996 of Melbourne secondary schools which found that schools did not have adequate resources of either hardware or skills to develop and teach projects in the computing field (Abramson, Lowe \& Atkinson, 2000).

\section{Understanding of the tertiary teaching and learning environment}

Students entering university from school need to adapt to new and different teaching and learning environments. The classes at university, for example lectures and computer laboratory classes, are generally 
unlike anything the students have experienced at school. Kantanis (2000) reports that students find the style and pace of learning is different from what is typically found at secondary school level, and many students have difficulty adjusting to the independent learning style that is expected at university. The study by McInnis, James and Hartley (2000) showed that many students find university more demanding than school. In 1995 a collaborative project between FIT and the Faculty of Education investigated the teaching and learning of programming in first year computing programs within FIT. This highlighted the problems faced by first year students and the difficulties they had coping with the demands and expectations of the unfamiliar tertiary learning environment (Hagan \& Macdonald, 2000; Sheard, Hagan \& Macdonald, 1997).

\section{Awareness of career opportunities}

Many students receive inadequate career counselling prior to commencing university and consequently have no clear picture of what career options their chosen degree program will provide (Peel, 1998a). Lack of adequate career counselling can lead to misconceptions about career directions, which may result in disenchantment and failure. If students are unable to focus on a career goal, this can negatively affect their motivation to succeed in, or even complete a degree. The implications of lack of motivation were highlighted in the study of first year computing students by Sheard and Hagan (1998). This revealed that most of the students who had failed their first year programming subject were uncertain about what career they wanted or were interested in pursuing a career in another field.

Conversely, there are students who may be suited to a career in computing but, as a result of misconceptions about the field, choose to study in another discipline. For example, female students often do not consider a career in computing as an option. Teague (1998) maintains that many females perceive that they would not enjoy working in a computing job and some are influenced by stereotyping which tends to direct them to seek more traditionally female careers.

\section{Social Transition}

\section{Establishing a new social network}

The social transition from school to university provides the basis for a successful academic transition (Kantanis, 2000). Many students find tertiary study an isolating experience. Often students arrive at university without knowing anyone else in their degree program and sometimes on the whole campus, especially students from remote rural areas. Many find it difficult to make friends or build a social network. They miss the close contact with their teachers and the supportive network provided by the much smaller secondary school environment. These problems were highlighted in a study by Terenzini, Rendon, Upcraft, Millar, Allison, Gregg and Jalomo (1994, p61) where they interviewed students from a range of socio-economic backgrounds and cultures. They found that:

“...the transition from high school or work to college is an exceedingly complex phenomenon. The nature and dynamics of the process vary according to the student's social, family, and educational background; personality; educational and occupational orientations and aspirations; the nature and mission of the institution being attended; the kinds of peers, faculty, and staff members encountered; the purpose and nature of all those encounters, and the interactions of all these variables."

Ferguson (1997) points out that the establishment of a social and support network is a particular problem for female students, due to their under representation in computing courses. 


\section{Broadening the social experience}

Students entering university are often unaccustomed to the diversity of a typical university population. Students from private or country schools often mix in limited social circles and may not have had the opportunity to work with students of other cultural or social backgrounds; students who have attended single sex schools have not usually experienced interactions in a work or study situation with students of the opposite sex (Clayton, Cranston, Laver \& Lynch, 1997).

\section{Adapting to the university environment}

The university campus is generally a large and overwhelming environment for new students. The study by Kantanis (2000) found that many students experience an extended, unsettled period of adjustment while they become familiar with the availability and location of resources, services and facilities.

\section{Tackling the Problem - an IT Summer School Project}

The Monash IT Summer School is a five day residential camp designed for students who are about to enter the final two years of their secondary schooling. All secondary schools in Victoria are invited to nominate two students to attend, and usually from 200 to 300 apply. The students are asked to write a short letter explaining their interest in attending the Summer School. The final selection of 60 students uses a stratified sampling technique designed to achieve equal numbers of male and female, metropolitan and country, and private and government funded school students.

The Summer School has as its main focus an IT related project that students work on for a total of 20 hours over the week of the Summer School. The selection of appropriate projects has been a non-trivial task. The project activities need to be easily understood by the students, hold their interest, have real application and be produced for a reasonable budget. A project developed for the inaugural Summer School in 1999, and which has been used in subsequent Summer Schools, is the Smart House project. This project is designed around a dolls' house set up as a computer controlled "smart house". The Smart House provides an ideal theme for a project demonstrating a real life application of computers and electronics (Abramson, Lowe \& Atkinson, 2000).

The Smart House project was designed to address the key academic and social transition issues identified earlier in this paper. The Smart House project activities incorporate elements of content from four degree programs within FIT. Specifically they include examples of computer hardware, program design, implementation and testing, project management, technical documentation and presentation. This provides students with an overview of tertiary computing course options and helps them gain an understanding of computing course content. In addition, students are given a learning experience in a tertiary teaching environment. During the project work they have interactions with other students and have many opportunities to talk to university teaching staff and current students.

The remainder of this section will provide an overview of the Smart House project and then descriptions of the learning and teaching environments, describing how they address the different aspects of trans ition.

\section{The Smart House Project}

\section{What is a "Smart House"?}

A Smart House is a house fitted with a variety of sensors and electronically operated devices that allow people to cus tomise their home. Using this system it is possible to monitor light level, temperature, window and door status and current occupants. With all this information available, a person could make a 
request like "if the children are home and it is after $4.00 \mathrm{pm}$, then ensure the temperature range is controlled between 16 and 18 degrees Celsius and pipe jazz music to the lounge room". Or alternatively, "if no occupants are home, lock all doors and windows, activate the alarm system and redirect all phone calls and intercom users to my mobile phone". Sensors and appliances can be monitored and controlled by a computer. Whilst such requests might seem fanciful, they will probably be seen as routine within our lifetimes (Abramson, Lowe \& Atkinson, 2000).

\section{Designing the Smart House}

The Smart House project designers realised that conceptualising a smart house was not going to be sufficient. Students would relate better to a 'real' system. However, the development of a life size smart house, room, or office would have been costly and not very portable. This problem was addressed by attaching various devices to a dolls' house to create the "Smart House". Devices used included sensors for light and temperature, fans, lights, intruder detection system, security door lock and doorbell. In addition, mains power nodes were produced to run stereos, fans and other household appliances to add some authenticity to the application. A detailed description of the Smart House concept is at: http://www.csse.monash.edu.au/transition/schools/smarthouse.html

\section{Project description}

The Smart House project required the students to design and develop their own customised smart house using the established dolls' house set up. This involved the following activities:

Building hardware. For the first activity of the project students worked individually to build a component of the hardware called the "Smart Node". A Smart Node is a microprocessor used to control the operation of various devices connected to the Smart House and was specifically developed for the Smart House system. The Smart Node was simple in layout and designed to be suitable for novices to assemble. Although it was anticipated that some students would be familiar with the electronic components, for most students this was their first experience in hardware construction and assembly.

Connecting the hardware. The students worked in pairs to connect their completed nodes to a computer and eventually built a small network with other nodes. By requiring students to be actively engaged in connecting the hardware components, they were more readily able to understand the relationship and functionality of the components and understand the application of hardware to the real world.

Smart House Designer software. When the hardware was assembled, the students worked in pairs to create their own solutions to a series of set problems, for example, cause the fans to switch on automatically when the temperature reaches a certain value. For this activity the students used the Smart House Designer. This is custom made software for the Smart House system that provides a link between the hardware and software using a graphical user interface (GUI). Most students were familiar with this style of interface from their experience with the Windows operating system and quickly used it to develop quite complex solutions (Proulx, Rasala \& Fell, 1996).

Group project. For the main activity of the project the students worked in groups of five to develop their own customised Smart Houses. For this task they were required to design, develop, test and document a Smart House system to an open ended specification. At the end of the Summer School, each group presented their own Smart House to other groups, parents and staff.

Programming in Visual Basic. The Smart House Designer software was written using the Visual Basic programming language. This language was chosen after a survey of schools in 1997 showed that many students had access to and had used Visual Basic. The students were given programming exercises designed to illustrate how components of the software were written and also to provide them with experience in programming, which is an important component of most computing degree programs. 


\section{The learning environment}

Learning experiences. For many of the students, the Summer School was their first visit to a university campus, and it was important that this was a positive experience for them. At the beginning of the first session an ice breaker activity was used. In undergraduate computing subjects, especially in first year, ice breakers are tools often used to help new students settle into university life (Carbone, Hagan \& Sheard, 1998). This was particularly useful for the Summer School, as the students chosen to participate included students from different cultures, gender, and from rural and city communities. This mix was potentially difficult for students unused to such social diversity.

For most of the project activities, the students worked in groups of five. This helped break down some of the social barriers and facilitated the sharing and discussion of ideas. Each group elected a project leader who was required to manage the project for the team. The groups were required to design and implement their own Smart House solution, and manage task allocations and the project schedule. This gave all the students experience in project management or observing project management first hand.

Students must adopt new and different learning strategies when they move from secondary school to university. In designing the Smart House project we endeavored to give the students an idea of the independent learning style required at university. To do this effectively, the students were given a loosely structured problem with outcomes that were achievable in the time available. After some preliminary instruction a problem was set, for example, design a system to protect the house against intruders, and the students were given time to solve it. A teacher was available to answer questions as they arose. Great pains were taken not to turn the classes into 'follow the recipe' sessions where students gain little understanding of principles underlying the practical work. The students were encouraged to manage their own learning as they are expected to do at university.

Learning resources. The survey of schools in 1996 showed that there was a huge variation in the students' knowledge of hardware and software. It was therefore important to allow the students to work at their own pace. To achieve this, detailed instructions of each activity were prepared for the students. Extra documentation with further explanation of the hardware was prepared for students who expressed a desire to learn more about the technical components.

At the completion of the Summer School, students took their Smart Node, Smart House software (on disks), documentation and other components home with them. This was to facilitate their further learning by enabling them to experiment with "smart" set-ups at home and school.

\section{The teaching environment}

Teaching space. Following recommendations of the Transition studies, students were given a realistic experience of a tertiary teaching environment. The project was conducted in a computer laboratory connected to the University network and with Internet access. The students also had the opportunity to experience a large lecture theatre - both as an audience and presenters. On the last day of the Summer School the students demonstrated their project work to other groups and parents in a high tech lecture theatre. Each group had a rehearsal before the presentation where technical staff explained the operation of the visual and sound equipment. The team members were also on hand to help set up the Smart House equipment. During the presentations the students operated the equipment with minimal help.

Teaching team. The Smart House project was designed to create an awareness of the variety of topics taught in four of the undergraduate degree programs offered by FIT and incorporated a range of activities that highlighted different aspects of these. Each session was taken by the team member who had most expertise in the particular activity. Therefore, over the course of the week, the students had an opportunity to meet and work with teachers from each degree program who were able to give first hand knowledge of their own program. In order to provide the students with a sense of continuity and ensure 
the cohesiveness of the project, the team leader was present for the introduction of each session, even when not actually conducting the session.

Transition studies have highlighted the importance of prospective students having contact with current students and academic staff to gain their perspectives (Peel, 1998b). At each session of the project the experienced teaching staff was assisted by postgraduate student demonstrators. The postgraduate students, being closer in age, interest, and outlook to the secondary school students, presented an image that the students were able to easily relate to. During the sessions, the postgraduate students informally discussed their undergraduate study and their future career plans with the students. Students were encouraged to ask questions and engage in discussion with teaching staff and each other following a fundamental teaching principle as described in Baird and Northfield (1992). The project sessions were lively affairs.

While postgraduate student demonstrators possessed the technical knowledge to conduct the workshops, they had little experience in teaching secondary school students. A special training session for the demonstrators was organised to review the secondary school student learning model and student expectations. A common trap is to assume the students have more familiarity with the material than they actually do. This can be exaggerated by the wide range of knowledge among the students themselves; some students had barely used computers before while others had installed network software for their home or school computers (Carbone, Hagan \& Sheard, 1998).

\section{Impact and Evaluation}

In this section the outcomes of the IT Summer School, focussing in particular on the Smart House project, are reported. The impact on the students' knowledge and understanding in the areas identified as being important for successful academic and social transition to tertiary education are described, and a follow-up study of the first cohort of Summer School students provides insights into how the Smart House project and Summer School experience ultimately assisted them in the settling in process in their first year of university. Furthermore, it is shown how the project activities, designed around fundamental teaching principles, successfully supported the learning process.

\section{Evaluation Methodology}

The evaluation methodology consisted of two studies: Study 1 assessed the immediate impact of the Smart House project and the IT Summer School on the 1999, 2000 and 2001 students $(\mathrm{n}=46)$, and Study 2 used a follow-up study of 1999 Summer School participants $(n=17)$ to assess the longer term impact of their Summer School and Smart House project experiences, and the success of their ultimate aim of assisting in the transition process to university.

Study 1 was conducted by administering a written questionnaire to students before and after each Summer School. This was supplemented with feedback from teachers and parents, and peer evaluation from the project team members and other colleagues. These provided us with quantitative and qualitative information about the immediate impact of the Smart House project and how the objectives were met.

Study 2 was a qualitative follow-up study of students from the 1999 Summer School when they were in their first year of university. A survey was conducted in mid second semester 2001, using semistructured phone interviews, and, in one case, an email questionnaire. Each student was asked about their first year university experiences that related to academic and social transitions. Students in this follow-up study were enrolled at Monash or other tertiary institutions.

The following sections describe the major findings from these two studies. 


\section{Study 1: Immediate Impact of the Smart House Project}

To determine the impact of the Smart House project, students were surveyed pre and post project in 1999, 2000 and 2001. The questionnaires contained questions that related directly to the objectives of the project and open-ended questions that sought undirected feedback from the students.

In an overall rating of the Smart House project on a Likert scale of 1 to 5 all students rated the Smart House project as 3 (Good) or above, with (33\%) of the students nominating 5 (Excellent). It was pleasing to find that in 2001 (55\%) of the students rated the project as excellent, showing a positive reaction to the improvements made in the project delivery from the feedback of previous years.

The pre and post project surveys enabled us to establish the impact of the program on the students' interest in computing as a study and career option. The students rated their interest in computing as a career on a 7-point Likert scale, where 1 indicates no interest and 7 indicates high interest. At the end of the Summer School students showed more interest in a career in computing $(M=5.58, s d=1.61)$ than at the $\operatorname{start}(M=5.13, s d=1.63)$. This difference was tested using a paired t-test ${ }^{1}$ and found to be significant $(t(30)=-2.96, p<0.05)$. In the post surveys students indicated that they would like a higher percentage of their university course to involve computing $(M=59 \%)$ than at the start $(M=54 \%)$, however this difference was not significant. The pre and post surveys also found gender differences in the interest in studying and pursuing a career in computing. Before the Summer School male students showed more interest than the female students, while at the end of the Summer School the interest of both groups had increased, with the males maintaining a greater interest than the females.

In the post survey questionnaire the students were also asked to indicate on a 7-point Likert scale $(1=$ nothing and $7=$ lots $)$ how much they felt they had learnt about different aspects of the project. There was also a not applicable option to select if they had not worked on a particular aspect. The results in Table 1 show that students felt that they had learnt a lot about most aspects of the project. The low rating for designing the presentation was probably because most students prepare presentations at school and this was not a new experience for them.

The qualitative feedback from the students indicated that significant immediate impact was achieved in terms of the major goals of the project in terms of academic and social transition issues. This was supported by feedback from teachers who observed the classes and parents. Some illustrative comments:

\begin{tabular}{|c|c|c|}
\hline Aspect of Smart House project & Mean & SD \\
\hline 1. Building the Smart Node. & 5.86 & 1.70 \\
\hline $\begin{array}{l}\text { 2. Working with the hardware } \\
\text { (connecting the nodes etc) }\end{array}$ & 5.93 & 1.14 \\
\hline $\begin{array}{l}\text { 3. Using the Smart House designer } \\
\text { software }\end{array}$ & 5.64 & 1.82 \\
\hline $\begin{array}{l}\text { 4. Designing your own Smart } \\
\text { House }\end{array}$ & 5.79 & 1.72 \\
\hline 5. Learning Visual Basic & 5.11 & 2.03 \\
\hline 6. Building a Web page & 6.00 & 1.23 \\
\hline 7. Designing the presentation & 3.92 & 2.23 \\
\hline 8. Producing the project report & 4.83 & 2.04 \\
\hline $\begin{array}{l}\text { 9. Researching Smart Houses on } \\
\text { the Web }\end{array}$ & 5.33 & 1.32 \\
\hline 10. Working in a group & 5.21 & 1.42 \\
\hline 11. Project management & 5.67 & 1.16 \\
\hline
\end{tabular}

\section{Table 1: Students' indications of how much they had learnt about different aspects of the $S$ mart House project}

"That there are so many new things that you would learn in uni that we haven't even covered at school and the opportunities at the uni for computing are just far better than at school." [Student]

\footnotetext{
${ }^{1}$ A t-test is a statistical method used to test for a significant difference between two means.
} 
"It has helped him explore other course options. He was not really interested in doing IT but I think this has shown him that it is possible to combine courses - maybe incorporate IT into or with another course. It is great to have the opportunity to speak to the students and teachers at university." [Parent]

"I found out what a real lecture is like, I'd never experienced one before. I learnt a bit about what living on campus is like, and what the size of the whole place is like; it wasn't that big after a while." [Student]

"Opened my eyes to the incredible range and variety of IT and the widespread, pervasive use of IT in all areas of commerce, industry, etc. More aware of how many women were involved in IT/industry/ academic and how equity (gender etc) is positively supported. Some great role models!" [Teacher]

The responses also indicated the impact of the project activities on the students' learning process. The whole Smart House environment, as a microcosm of the students' own home environments, allowed them to establish links between the project activities and the real-world. Their knowledge about household routines enabled them to readily understand the requirements of the project and what aspects of the Smart House would be useful to automate.

Active engagement was a theme throughout the project, through the Smart Node construction, Smart House Designer exercises, team-based design and development. As one observing teacher commented:

"Smart House had a good balance between doing and thinking - the kids were engaged early"

Student feedback clearly indicated that they enjoyed doing something practical and making something work, that they felt a real sense of achievement. Some typical comments from students were:

"I really liked using the program on the little house to make different things happen"

"Getting my team together and working, completing the project on time, and having our presentation run very smoothly - and work. My most memorable moment was how our smart-house worked first time, and without any problems"

"I didn't think I would be able to create something like that which worked! It was so great. Seeing it light up and make the sounds and stuff was really exciting"

Working with others was clearly a highlight of the project for many students as indicated by the following responses:

"Teamwork is something that I enjoy doing and it was different for me in this group cause I wasn't the one organising everything - very different for me - and I learnt that we all need to work together to get the best product"

"[Working in a group was] the best part of the whole thing. Great experience for me"

\section{Study 2: Longer Term Impact of the Smart House Project}

The ultimate success of the Smart House project can be demonstrated by how well the students event ually cope with the transition from school to university. In 2001, students from the first Summer School in 1999 began tertiary study, providing an opportunity to determine the longer-term impact of the program. Ten 1999 Smart House project students were interviewed by phone. In addition we also interviewed seven other 1999 Summer School students who are enrolled at Monash. Of the students interviewed, 11 were studying at Monash and six were at other institutions. In this group there were 10 males 
and seven females. As our study is focussing on the Smart house project, the comments shown below are from the Smart House students.

Upon reflection, students were unanimously positive about the 1999 Summer School and the Smart House project. Typical comments were: "a really happy experience", "heaps of great memories" and "very positive experience". For many it was also a motivating experience. One student found the Summer School inspiring and useful; others commented that they felt more motivated to work harder at school and further their studies at university. Most also remembered the Smart House project as a highlight:

"Smart House project was interesting ... I didn't get bored at all ... something different to do each day"

"I took a Smart node home and got it working ... have done lots of things with it ... gave me an interest in this area"

"I learnt a lot about technology"

We report the students' comments under the various academic and social factors that we have identified as influencing transition. Although the number of students $(n=17)$ is too small to make generalisations from, when compared with results from other transition studies, the Smart House project students ind icated more positive attitudes, experiences and outcomes from their first semester university experiences than the typical first year university population. Furthermore, we note that while the sample size is too small to be statistically significant, none of the students we contacted had discontinued with their course which compares favorably with dropout rates of more than $10 \%$ experienced across courses within our Faculty by the end of first semester.

\section{Academic transition}

Overall most students indicated they had had successful transitions to university. All commented upon the differences between school and university and the adaptations needed upon moving to the tertiary environment, however most indicated that by second semester they had settled in. Most of the Monash students contacted were satisfied with their first semester results, and at that stage none had dropped out of their chosen degree or indicated any intention of doing so. The students showed more positive reactions and outcomes from their first semester at university than have been found by students in other studies (McInnis, James \& Hartley, 1999). Their responses are considered under the various areas identified earlier in this paper.

Satisfaction with the tertiary teaching and learning environment. All students surveyed maintained that by second semester they were comfortable with the tertiary teaching and learning environment. Although some students found the workload heavy and adapting to the independent learning style expected was an issue, many affirmed that the Summer School had prepared them for these changes and that knowing what to expect had helped them settle in.

"the university environment is rougher ...you are not as well looked after as you are at school. This was an issue for the first week - after that you get used to it. The Summer School helped - it gave us a good idea what to expect"

"the Smart House project gave us an understanding how to work with little direction we were given a task and had to work it out for ourselves with minimal help"

"at the Summer School you were able to talk to the teachers to get an idea of what they expect...how they are going to teach you" 
Satisfaction with their degree program selection. Most students indicated that the Summer School experiences had influenced their final decision about degree programs and university. A number of students remarked that they appreciated the opportunities they had had at the Summer School to talk to staff and postgraduate students about their own programs. For some, this had initiated an interest in IT. Considering that research studies have shown that female students often perceive that a comput ing course would not interest them (as described earlier), it was interesting that both male and female students had been influenced. One female student stated that the Summer School had "opened her eyes" to the Computer Science degree she is currently enrolled in. Another commented that the Summer School had given her an understanding of what a computing degree involved and maintained that it definitely influenced people to do IT. More than half of the students from the 1999 Summer School chose computing degrees. A number of other students enrolled in degree programs with a significant component of IT, a couple indicating that they had discovered at the Summer School how IT could be combined with, or studied within other courses. This helped them in the process of choosing a degree program that most closely matched their interests.

"Big fan of computers and I was heading in IT direction ....at the Summer School I learnt that IT is not just about computers and I chose electrical engineering"

Most students indicated that the major factors in their choice of university degree were interest and enjoyment and it is therefore pleasing that most students were satisfied with their program selection.

After the Summer School some students realised that IT was not their area of interest, and this was a valuable outcome for them as it helped them make a more informed decision. One student commented:

"after I did the Summer School I realised I didn't want to do IT - I couldn't get my head around it"

Satisfaction with degree program content. All students who enrolled in computing degree programs indicated that they were satisfied with the content of their program.

"couldn't be happier (with my degree program) - even with 26 contact hours"

"I am very happy with my course - I am learning a great deal of things"

Satisfaction with career prospects. Nearly all students interviewed had knowledge of the career outcomes of the degree program they were enrolled in. In particular the students enrolled in computing programs, many of whom indicated that the Summer School had increased their awareness of the career possibilities in this discipline.

"opened my eyes to IT and the broad range of opportunities"

"helped me with choice of course and career"

"opened my mind to possibilities for courses and career - I was not interested in IT before the Summer School"

\section{Social transition}

The Summer School was a wonderful social event for the students. The experience of living on campus for a week with 60 other students of the same age, but from all types of schools and backgrounds, was a memorable experience for most. Many spoke enthusiastically about the people they met and the friends they had made. The impact of the Summer School is considered under the various areas identified earlier in this paper.

Establishing a new social network. All students at Monash and most students at other institutions were content with their new social networks. Many have kept in contact with other Summer School students, 
however, understandably the students at Monash now have more contact on campus. There were indications that this was a factor in their successful social adaptation to university.

"it was like starting out again as a little fish in a big pond - seeing others I knew from the Summer School helped”

"I have made the transition well - thanks to knowing people in my course from the Summer School"

Living on campus was a highlight for most. This was particularly useful for country students in preparing them for their move away from home to attend university. Many commented how the Summer School helped them understand what living on campus was like.

Adapting to the broader social context of the university environment. All students surveyed were comfortable with the new broader social context of their university environment. Various comments indicated that the Summer School had prepared them for the diverse university environment.

A female student who came from a small ethnic school found "the mix of races and cultures at university a bit of a shock", but stated that "the Summer School helped prepare me for the range of people I would be surrounded by at university"

A student who attended an all boys school found that "girls in classroom was different - [the Summer School] helped my communication skills with girls"

"gave me the opportunity to meet other people interested in IT...at my school there weren't many others interested in IT ... it was great being with other people interested in IT"

Adapting to the diverse physical university environment. All students at Monash and most students at other institutions were comfortable with the university grounds and layout. Those students at Monash especially found the transitions easy, one student remarking that there was almost no 'transition' given the exposure they had to the campus in the Summer School. One student appreciated the opportunity the Summer School gave to explore Monash. It was pleasing to hear their favourable comments of Monash in reflection:

"really impressed with Monash - could tell they have a really good set up"

"impressed with the facilities - seeing it was a big plus"

\section{Conclusion and Longer Term Future for the Project}

The Smart House project was designed for the Monash IT Summer School for secondary school students, to enthuse, inform and facilitate the transition to tertiary education. The Summer School program takes a different approach to the transition problem by addressing the problem before the students arrive at university. The intensive program benefits a small number of students directly, however the impact is farther reaching, as students in the program return to school, friends and family reporting on their experiences.

While the surveys of students at the end of each Summer School and evaluation of feedback from parents and teachers indicates that the Smart House project, as part of the IT Summer School program, has been successful in meeting its objectives of addressing transition issues of future computing students, it is the follow-up study which has established its success. The survey of students who are now at university has highlighted the importance of tackling the transition issue before students arrive at university. Much can be done ahead of time to prepare students and ensure their future success in their chosen tertiary degree program. 


\section{Acknowledgements}

We would like to thank David Abramson who established the project to build the Smart House and was involved in every stage of its development. We would also like to thank Greg Watson who wrote the Smart House control software and Peter Atkinson and Gary Evans who designed and built the hardware.

\section{References}

Abramson, D. A., Lowe, G. \& Atkinson, P. (2000). Are you interested in computers and electronics? Proceedings of the 4th Australasian Computing Education Conference, Monash University, December 2000.

Baird, J. R. \& Northfield, J. R. (Eds) (1992). Learning from the PEEL experience. Melbourne: Monash University.

Braxton, J., Vesper, N., \& Hossler, D. (1995). Expectations for college and student persistence. Research in Higher Education, 36 (5), 595-612.

Carbone, A., Hagan, D. \& Sheard, J. (1998). Consolidate, preserve and build; A tutor training program for a new school. Proceedings of the 3rd Australasian Conference on Computer Science Education, Brisbane.

Clayton, D., Cranston, M., Laver, N. \& Lynch, T. (1997). WICNET: Supporting women computing students using an electronic mailing lis t. Proceedings of the Fourth Australian Women in Computing Workshop (WIC'97), Technical Report 97/319, Department of Computer Science, Monash University, 28-35.

Ferguson, T. (1997). Developing an inclusive information technology curriculum for an inclusive information technology industry. Proceedings of the Fourth Australian Women in Computing Workshop (WIC'97), Technical Report 97/319, Department of Computer Science, Monash University, 43-47.

Gale, A., Andrews, P., Biddle, R. \& Brown, J. (1997). Computer science retention and recruitment at VUW. Proceedings of the Fourth Australian Women in Computing Workshop (WIC'97), Technical Report 97/319, Department of Computer Science, Monash University, 20-26.

Hagan, D. \& Macdonald, I. (2000). A collaborative project to improve teaching and learning in first year programming. Australasian Journal of Engineering Education. Published by Australasian Association for Engineering Education Inc, Melbourne, Australia, 9(1), October, 2000, 65-76.

James, R. (2000). How school-leavers choose a preferred university course and possible effects on the quality of the school university transition. Journal of Institutional Research, 9 (1), 78-88.

Kantanis, S. T. (2000). The role of program cohesion in effecting a smooth transition from secondary school to university. Journal of Institutional Research, 9 (1), 100-110.

McInnis, C. \& James. R. (1995). First year on campus: diversity in the initial experiences of Australian undergraduates. Canberra, Australia: Australian Government Publishing Service.

McInnis, C., James, R. \& Hartley, R. (2000). Trends in the first year experience in Australian universities. Centre for the Study of Higher Education, University of Melbourne. Department of Education Training and Youth Affairs, Canberra, Australia.

Pargetter, R. (1995). Transition research, analysis and strategy. Keynote address at the Monash University Conference on the Transition from Secondary School to University, Monash University, Melbourne.

Pascarella, E. T. \& Terenzini, P. T. (1991). How College Affects Students: Findings and Insights from Twenty Years of Research. San Francisco: Jossey-Bass. ISBN: 1-55542-304-3.

Peel, M. (1998a). The transition from year twelve to university. Report on the Monash Transition Program.

Peel, M. (1998b). Monash transition program, goals and strategies. November 1998.

Proulx, V., K., Rasala, R. \& Fell, H. (1996). Foundations of computer science: what are they and how do we teach them? Integrating Technology into Computer Science Education, Barcelona, Spain.

Reality Bytes. (2001) An in-depth analysis of attitudes about technology and career skills. Communications Division, Mult imedia Victoria.

Sheard, J., Hagan, D. \& Macdonald, I. (1997). Designing and developing a new learning environment for teaching introductory programming: change for effect. Proceedings of World Multiconference on Systemics, Cybernetics and Informatics, Caracas, Venezuela. 
Sheard, J. \& Hagan, D. (1998). Our failing students: A study of a repeat group. Proceedings of ITiCSE '98, Dublin, Ireland.

Terenzini, P., Rendon, L., Upcraft, M., Millar, S., Allison, K., Gregg, P. \& Jalomo, R. (1994). The transition to college: Diverse students, diverse stories. Research in Higher Education, 35 (1), 57-73

Teague, J. (1998). Women in computing: what brings them to it and what keeps them in it? Proceedings of the 5th Australasian Women in Computing Workshop.

\section{Biographies}

The team members received an Excellence in Teaching and Innovation Award in 2000 from the School of Computer Science and Software Engineering, and a Vice Chancellor's award for Team-based Educational Development in 2001.

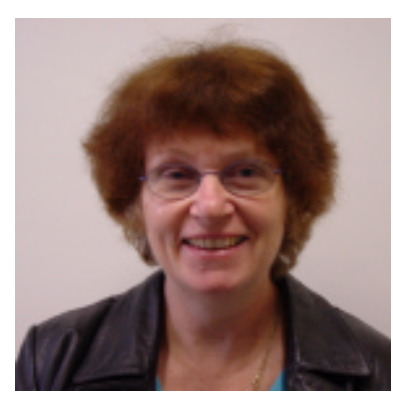

Judy Sheard is a Senior Lecturer in the School of Computer Science and Software Engineering at Monash University. Judy spent seven years in industry as a programmer before resigning to work as a full time parent for ten years. During the past 14 years at Monash she has taught programming to all le vels of undergraduate and graduate level students. Judy has published over 30 papers in international conferences and journals. Her main research interest is investigating issues around the Web as a new educational medium. In 2001 she established the Monash Museum of Computing History. Judy was Program Chair for the 4th Australasian Computing Education conference and a co-organiser for the 7th Women in Computing forum, both held in Melbourne, Australia, in 2000.

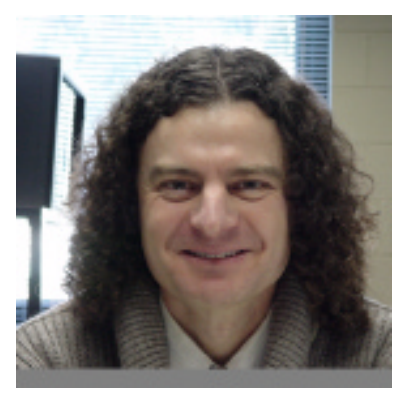

Gordon Lowe is a Lecturer in robotics in the School of Computer Science and Software Engineering at Monash University. Gordon has many years of industrial experience as an engineer in roles including project work, automation consultant, and applications engineering. He left industry in 1991 to become a lecturer in robotics at Monash University and has gone on to teach in a diverse range of subjects. His current teaching research interest is telerobotics as a laboratory teaching tool to assist students control their own learning experience.

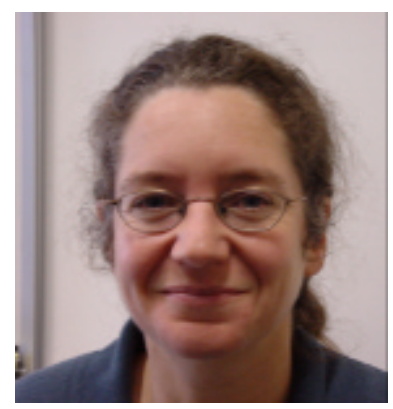

Ann Nicholson is a Senior Lecturer in the School of Computer Science and Software Engineering at Monash University. She did both an undergraduate B.Sci(Hons) degree, majoring in Computer Science, and a Master of Science degree at the University of Melbourne. Ann was awarded the 1988 Victorian Rhodes Scholarship to the University of Oxford, where she undertook her doctorate in the Robotics Research Group. She also worked as a post-doctoral researcher at Brown University. Ann has published more than 40 refereed papers in international journals and conferences in the field of Artificial Intelligence

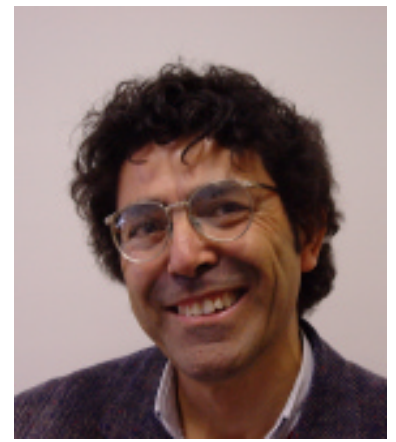

Jason Ceddia is a Lecturer for the School of Computer Science and Software Engineering. Jason has extensive teaching experience, having taught at TAFE, College of Advanced Education (Victoria College) and tertiary levels. He has taught a wide range of subjects from programming (in many languages), hardware operation, operating systems and project management; the teaching has been from first year through to honours. In recent years, Jason has been responsible for final year student projects and has developed a web based tool to enable collaboration from the multiple stakeholders at different locations. 